\title{
Farmers' market shopping and dietary behaviours among Supplemental Nutrition Assistance Program participants
}

\author{
Stephanie B Jilcott Pitts ${ }^{1, *}$, Qiang Wu ${ }^{2}$, Chelsea L Demarest ${ }^{1}$, Crystal E Dixon ${ }^{1}$, \\ Ciarra JM Dortche ${ }^{1}$, Sally L Bullock ${ }^{3}$, Jared McGuirt ${ }^{3}$, Rachel Ward ${ }^{4}$ and \\ Alice S Ammerman ${ }^{3}$ \\ 'Department of Public Health, Brody School of Medicine, East Carolina University, 600 Moye Blvd, MS 660, \\ Lakeside Annex 7, Greenville, NC 27834, USA: ${ }^{2}$ Department of Biostatistics, East Carolina University, Greenville, \\ NC, USA: ${ }^{3}$ Department of Nutrition, University of North Carolina at Chapel Hill, Chapel Hill, NC, USA: ${ }^{4}$ Department \\ of Community Health, East Tennessee State University, Johnson City, TN, USA
}

Submitted 3 March 2014: Final revision received 2 February 2015: Accepted 24 February 2015: First published online 21 April 2015

\begin{abstract}
Objective: Because farmers' markets include a variety of fruits and vegetables, shopping at farmers' markets would likely improve diet quality among lowincome consumers, as well as promote sustainable direct farm-to-consumer business models. However, not much is known about how to promote farmers' market shopping among low-income consumers. Therefore, the purpose of the present paper was to examine barriers to and facilitators of shopping at farmers' markets and associations between shopping at farmers' markets and self-reported dietary behaviours (fruit and vegetable, sugar-sweetened beverage and fast-food consumption) and BMI.

Design: Cross-sectional analyses of associations between farmers' market shopping frequency, awareness of markets, access to markets, dietary behaviours and BMI.

Setting: Department of Social Services, Pitt County, eastern North Carolina, USA. Subjects: Between April and July 2013, Supplemental Nutrition Assistance Program (SNAP) participants ( $n$ 205) completed a quantitative survey.

Results: Barriers to shopping at farmers' markets included does not accept SNAP/ electronic benefit transfer, out of the way and lack of transportation. Farmers' market shopping was associated with awareness of farmers' markets (estimate $=0 \cdot 18$ (sE $0 \cdot 04), P<0 \cdot 001)$. Fruit and vegetable consumption was positively associated with farmers' market shopping (estimate $=1.06$ (sE 0.32), $P=0 \cdot 001$ ).

Conclusions: Our study is one of the first to examine SNAP participants' farmers' market shopping, distance to farmers' markets and dietary behaviours. Barriers to shopping at farmers' markets and increasing awareness of existing markets should be addressed in future interventions to increase SNAP participants' use of farmers' markets, ultimately improving diet quality in this high-risk group.
\end{abstract}

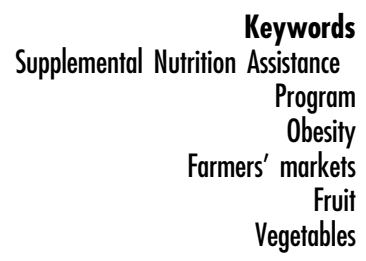

While the Supplemental Nutrition Assistance Program (SNAP) was created to mitigate hunger and improve health among the nation's poor, SNAP has come under scrutiny as some studies have shown that participants' dietary behaviours and weight status are less healthy than their income-eligible, non-SNAP participant counterparts ${ }^{(1-7)}$. SNAP participants have lower overall diet quality ${ }^{(2-5)}$ resulting in higher adiposity (as measured by BMI and waist circumference) when compared with their incomeeligible non-SNAP participant counterparts ${ }^{(6-8)}$. Obesity and chronic disease risk are potentially ameliorated by higher diet quality, including more fruit and vegetable (FV) consumption and less sugar-sweetened beverage (SSB) and fast-food consumption ${ }^{(9-12)}$. Increasing FV consumption is a worthy public health nutrition goal, as many FV are classified as both healthy and sustainable foods ${ }^{(13)}$. One study found that limiting consumption of red meat and eating more FV could substantially reduce an individual's food-related greenhouse gas emissions ${ }^{(14)}$. Therefore, efforts to promote healthier food consumption among SNAP participants are greatly needed.

Both financial access and geographic access to healthy foods are important determinants of $\mathrm{FV}$ consumption. More specifically, FV consumption in low-income 
populations may be greater when fresh produce is more accessible ${ }^{(15-17)}$. Farmers' market shopping among lowincome consumers would likely increase these individuals' FV consumption, as well as improve local economies through promotion of sustainable direct farmer-toconsumer marketing efforts. A joint statement by the Academy of Nutrition and Dietetics, the American Nurses Association, the American Planning Association and the American Public Health Association defined a sustainable food system as one that 'conserves, protects, and regenerates natural resources, landscapes and biodiversity' and 'meets our current food and nutrition needs without compromising the ability of the system to meet the needs of future generations ${ }^{(18)}$. Farmers' markets often sell locally grown products and many farmers who sell at markets practise sustainable farming techniques, which protect natural resources and conserve farmland for future food needs ${ }^{(19)}$. Thus, local farmers' markets are a crucial part of a healthy, sustainable food system. However, not much is known about whether shopping at farmers' markets is associated with better diet quality ${ }^{(20,21)}$, and if so, how to promote shopping at farmers' markets among low-income consumers.

To help overcome these barriers, creative interventions have been developed. 'Double Bucks' and similar interventions, whereby low-income individuals' SNAP benefits are multiplied when used at local farmers' markets, have shown promise. In Philadelphia, Young et al. found that when SNAP participants were given incentives to spend \$US 5 of SNAP benefits at a local farmers' market, SNAP transactions increased and participants reported consuming more $\mathrm{FV}^{(22)}$. In New York City, 'Health Bucks' resulted in greater SNAP benefit redemption in markets ${ }^{(23)}$. As part of a large initiative funded by the Centers for Disease Control and Prevention, North Carolina's Community Transformation Grant Project (NC CTG-Project) is seeking to increase farmers' market use among North Carolina residents and particularly among those at greatest risk for obesity ${ }^{(24)}$. Research suggests a relationship between voucher programmes, farmers' market use and improved diet ${ }^{(22,23)}$, yet more evidence in a variety of settings is needed.

Despite the fact that shopping at farmers' markets is a cost-effective way for individuals of limited income to purchase and consume recommended amounts of $\mathrm{FV}^{(25)}$, there are barriers to farmers' market shopping, such as lack of awareness of market locations, lack of ability to redeem SNAP benefits at markets and lack of transportation to markets ${ }^{(26,27)}$. Given national proposals for support of Double Bucks at farmers' markets ${ }^{(28)}$, more research is needed to better understand and identify barriers to the use of SNAP benefits at farmers' markets, as efforts to promote increased $\mathrm{FV}$ consumption through the use of farmers' markets will be ineffective if barriers are not addressed. Furthermore, it is important to learn about barriers to and facilitators of farmers' market shopping among SNAP participants because state-wide CTG-Project efforts are underway to increase accessibility and promotion of markets, particularly for low-income consumers ${ }^{(24)}$. Thus, we conducted a quantitative survey to examine farmers' market shopping patterns, awareness of the location of farmers' markets, perceived $v$. objective access to markets, and barriers to and facilitators of shopping at farmers' markets among SNAP participants in eastern North Carolina. We also examined associations between farmers' markets shopping and self-reported dietary behaviours (including FV, SSB and fast-food consumption) and BMI.

\section{Methods}

\section{Study setting and participants}

The present study was conducted as part of an evaluation of NC CTG-Project Farmers' Market Initiatives. The study was set in Pitt County, a county with a small urban centre and large surrounding rural area in eastern North Carolina. We recruited SNAP participants from the Pitt County Department of Social Services waiting room. Participants were eligible if they were English speakers, received SNAP benefits, over 21 years of age and a primary food shopper for the household. A consent form was provided to eligible individuals who were interested in participating in the study. Potential participants were asked if they had any study-related questions. Interested individuals signed an informed consent form. A \$US 10 gift card to a local supercentre was provided upon survey completion. The East Carolina University Institutional Review Board approved the study.

A screening form was used to track eligibility and refusal data. Of 298 screened, two were not eligible because they were not a primary household food shopper; eleven were not eligible because they were not 21 years of age or older; forty-five were not eligible because they did not currently receive SNAP benefits; and thirty-five refused.

\section{Study survey}

Participants were offered a chance to complete the faceto-face survey on their own or have it administered by the interviewer. The surveys took $20-40 \mathrm{~min}$ to complete depending on mode of administration, literacy level of the participant and if the participant had distractions (e.g. being called up to the desk, had children to watch while completing the survey). The survey assessed farmers' market shopping frequency, shopping at various markets throughout Pitt County, awareness of markets, access to markets, and barriers to and facilitators of use of farmers' markets. The survey also assessed dietary behaviours such as FV, SSB and fast-food consumption. Items on the survey are described in greater detail below.

Farmers' market shopping, awareness and access Participants were asked 'How often in the past 12 months did you buy fruits or vegetables that were locally grown 
from a farmers' market, community-supported agriculture (CSA), roadside stand, or pick-your-own produce farm? ${ }^{\text {,(16) }}$ Answer choices ranged from two or more times per week to never. Due to distribution of responses, 'farmers' market shopping' was dichotomized into never $v$. ever purchasing produce from a farmers' market in the past 12 months.

Farmers' market awareness was assessed by asking participants to mark a box beside each of sixteen Pitt County markets if they had 'heard of it before' and if they 'knew how to find' the market (i.e. knew where the market was located). The positive responses were summed to create an awareness score, ranging from 0 to 32, as used in prior research ${ }^{(16)}$. We calculated the mean awareness score, as well as the number of participants who were aware of the market closest to home. Participants were also asked to check a box beside each of the sixteen markets they had shopped at before.

Farmers' market access (objectively measured and perceived) was quantified in the following four ways: (i) the mean distance (using the road network) from the participants' residential address to all markets that the participants used was calculated using Google Application Programmable Interface (API); (ii) participants were asked at which market in Pitt County they shopped the most frequently and the distance from their residential address to this specific market of their choosing was calculated using Google API; (iii) participants were asked to estimate the travel distance from their residential address to the most frequently visited market; and (iv) the minimum distance from the residential address to the closest market was calculated using Google API. The first, second and fourth methods were objective measures, while the third was a self-reported, perceived measure of access. We also examined the number of participants who shopped at the farmers' market that was closest to their residential address.

Facilitators of use of farmers' markets were measured by asking, "What is the main reason you shop at this or another farmers' market? If you never shop at farmers' markets, what is the main thing that would motivate you to shop at farmers' markets?' This question was followed by a list of possible facilitators, informed by prior studies ${ }^{(26,27)}$. For barriers, participants were asked, 'What is the main thing that stops you from shopping at farmers' markets?' This question was followed by a list of possible barriers. For both the facilitators and barriers questions, participants could hand-write in unlisted facilitators or barriers. Participants selected their top three barriers and top three facilitators.

\section{Dietary behaviours}

FV consumption was assessed using the validated Block Fruit, Vegetable, and Fiber screener ${ }^{(29,30)}$. FV servings per day were calculated using the standard protocol, summing responses to the seven fruit and vegetable items and using Nutrition Quest's age- and gender-specific equations ${ }^{(29,30)}$.
Because declines in obesity prevalence are dependent on substitution of more healthful foods such as FV for less healthful foods such as energy-dense, nutrient-poor foods like SSB and fast foods ${ }^{(31)}$, we measured not only FV consumption, but also SSB and fast-food consumption. The underlying hypothesis is that individuals who shop at a farmers' market would become more interested in eating healthfully, and would thus displace unhealthy food and beverage consumption with healthier consumption patterns. SSB consumption was measured using the validated Beverage Intake Questionnaire $(\mathrm{Bev}-\mathrm{Q})^{(32)}$. The Bev-Q includes nineteen beverage items ranging from water to sugar-sweetened beverages, milk, alcohol and energy drinks. The respondent provided the frequency with which each beverage item was consumed, and if consumed, the amount consumed each time. Fast-food consumption was measured using eight-items that were used in the Michigan Behavioural Risk Factor Surveillance system $^{(33)}$. For the purposes of the present study, to quantify fast-food consumption, we used responses from a single question from the eight-item scale ('How often do you usually go to a fast-food restaurant, like McDonalds, Hardee's or Burger King?') and respondents could answer times per day, week or month.

\section{$B M I$}

BMI was calculated using self-reported height and weight, and corrected for systematic error (under-reporting of weight among overweight and obese individuals and based upon demographic characteristics) using age, race and $\operatorname{sex}^{(34)}$. We used both corrected and uncorrected BMI in analyses.

\section{Statistical analysis}

Means and standard deviations were calculated for continuous variables, and frequencies and percentages were calculated for categorical variables. We examined differences in various demographic characteristics and dietary behaviours between those who reported never $v$. ever shopping at farmers' markets using Mann-Whitney $U$ tests for continuous variables and $\chi^{2}$ tests for categorical variables. In multiple logistic regression analyses with farmers' market use (dichotomous) as the dependent variable, the independent variables were farmers' market awareness and the four access variables (continuous). In multiple linear regression analyses with dependent variables of BMI, FV, SSB and fast-food consumption, the independent variable was farmers' market use. All analyses were adjusted for race (black or non-black), age (continuous in years), education (high school or college or greater), sex (male or female) and public transportation (yes or no) to indicate whether or not individuals used public transportation. Alpha was set at 0.05 to indicate statistical significance. Analyses were conducted in the SAS statistical software package version 9.2. 


\section{Results}

\section{Participant characteristics}

Table 1 lists participant demographic characteristics ( $n$ 205). Mean age was 37.5 years and mean BMI was $32.9 \mathrm{~kg} / \mathrm{m}^{2}$. Three-quarters of participants were black, $84 \%$ were female and $56 \%$ had a high-school education or less. SNAP participants self-reported eating 4.0 servings of $\mathrm{FV}$ per day (as assessed using the Block Screener), $1958 \mathrm{~kJ} / \mathrm{d}$ ( $468 \mathrm{kcal} / \mathrm{d}$ ) from SSB, and $91 \%$ reported ever eating fast food. Of the 205 participants completing the main questionnaire, a sub-sample of 106 participants completed the SSB and fast-food questionnaire ( $n 98$ and $n 93$ because of missing responses for SSB or fast-food questions).

Table 1 Participant characteristics among Supplemental Nutrition Assistance Program participants, and differences between those who reported never $v$. ever shopping for produce at farmers' markets in the past 12 months, eastern North Carolina, USA, April-July 2013

\begin{tabular}{|c|c|c|c|c|c|c|}
\hline Characteristic & $N$ & Mean & SD & $\begin{array}{l}\text { Mean for those who never } \\
\text { shop at farmers' markets }\end{array}$ & $\begin{array}{l}\text { Mean for those who ever } \\
\text { shop at farmers' markets }\end{array}$ & $\begin{array}{l}P \text { value for } \\
\text { difference }\end{array}$ \\
\hline Age (years) & 198 & 37.5 & $13 \cdot 3$ & $36 \cdot 7$ & $38 \cdot 6$ & 0.33 \\
\hline BMl $\left(\mathrm{kg} / \mathrm{m}^{2}\right)$, uncorrected & 191 & $32 \cdot 0$ & $8 \cdot 1$ & 31.6 & $32 \cdot 2$ & 0.84 \\
\hline BMI $\left(\mathrm{kg} / \mathrm{m}^{2}\right)$, corrected & 190 & $32 \cdot 9$ & $8 \cdot 2$ & $32 \cdot 6$ & $33 \cdot 1$ & 0.82 \\
\hline FV consumption (servings/d) & 205 & $4 \cdot 0$ & $2 \cdot 3$ & $3 \cdot 6$ & $4 \cdot 7$ & $<0.01$ \\
\hline \multicolumn{7}{|l|}{ SSB consumption } \\
\hline $\mathrm{kJ} / \mathrm{d}$ & 98 & $1958 \cdot 5$ & $2050 \cdot 2$ & $2232 \cdot 2$ & $1666 \cdot 5$ & 0.08 \\
\hline $\mathrm{kcal} / \mathrm{d}$ & 98 & $468 \cdot 1$ & $490 \cdot 0$ & 533.5 & $398 \cdot 3$ & 0.08 \\
\hline Fast-food consumption (times/d) & 93 & 0.39 & 1.08 & 0.47 & 0.32 & 0.77 \\
\hline $\begin{array}{l}\text { Farmers' market awareness } \\
\text { score (range 0-32) }\end{array}$ & 205 & $5 \cdot 2$ & $6 \cdot 8$ & $2 \cdot 9$ & $8 \cdot 1$ & $<0.01$ \\
\hline \multicolumn{7}{|l|}{$\begin{array}{l}\text { Distance to closest farmers' } \\
\text { market }\end{array}$} \\
\hline $\mathrm{km}$ & 190 & 4.5 & $4 \cdot 3$ & $4 \cdot 2$ & $5 \cdot 1$ & 0.02 \\
\hline miles & 190 & $2 \cdot 8$ & $2 \cdot 7$ & $2 \cdot 6$ & $3 \cdot 2$ & 0.02 \\
\hline \multicolumn{7}{|l|}{$\begin{array}{l}\text { Distance to most frequented } \\
\text { farmers' market }\end{array}$} \\
\hline km & 71 & $15 \cdot 0$ & $10 \cdot 5$ & - & - & - \\
\hline miles & 71 & $9 \cdot 3$ & $6 \cdot 5$ & - & - & - \\
\hline \multicolumn{7}{|l|}{$\begin{array}{l}\text { Average distance to visited } \\
\text { farmers' markets }\end{array}$} \\
\hline $\mathrm{km}$ & 60 & $14 \cdot 3$ & $7 \cdot 1$ & - & - & - \\
\hline miles & 60 & 8.9 & 4.4 & - & - & - \\
\hline \multicolumn{7}{|l|}{$\begin{array}{l}\text { Self-reported distance to most } \\
\text { frequented farmers' market }\end{array}$} \\
\hline $\mathrm{km}$ & 81 & $19 \cdot 8$ & $27 \cdot 5$ & - & - & - \\
\hline \multirow[t]{2}{*}{ miles } & 81 & $12 \cdot 3$ & $17 \cdot 1$ & - & - & - \\
\hline & $N$ & Frequency & Percentage & $\begin{array}{l}\text { Percentage for those who } \\
\text { never shop at farmers' } \\
\text { markets }\end{array}$ & $\begin{array}{c}\text { Percentage for those who } \\
\text { ever shop at farmers' } \\
\text { markets }\end{array}$ & $\begin{array}{l}P \text { value for } \\
\text { difference }\end{array}$ \\
\hline Race & 197 & & & & & \\
\hline Black & & 150 & $76 \cdot 1$ & $79 \cdot 3$ & $70 \cdot 7$ & $0 \cdot 18$ \\
\hline Non-black & & 47 & 23.9 & $20 \cdot 7$ & $29 \cdot 3$ & \\
\hline Sex & 197 & & & & & \\
\hline Male & & 32 & $16 \cdot 2$ & $15 \cdot 5$ & $18 \cdot 1$ & $0 \cdot 70$ \\
\hline Female & & 165 & $83 \cdot 8$ & 84.5 & 81.9 & \\
\hline \multicolumn{7}{|l|}{ Education } \\
\hline High-school graduate or less & 198 & 111 & $56 \cdot 1$ & $57 \cdot 7$ & 54.2 & 0.66 \\
\hline Some college or more & & 87 & 43.9 & $42 \cdot 3$ & $45 \cdot 8$ & \\
\hline Fast-food consumption & 93 & & & & & \\
\hline None & & 9 & $9 \cdot 7$ & $10 \cdot 9$ & 8.9 & 1.00 \\
\hline Any & & 84 & $90 \cdot 3$ & $89 \cdot 1$ & $91 \cdot 1$ & \\
\hline $\begin{array}{l}\text { Farmers' market shopping in the } \\
\text { past } 12 \text { months }\end{array}$ & 199 & & & & & \\
\hline None & & 114 & $57 \cdot 3$ & - & - & - \\
\hline Any & & 85 & $42 \cdot 7$ & - & - & \\
\hline $\begin{array}{l}\text { Farmers' market shopping in the } \\
\text { past } 12 \text { months }\end{array}$ & 199 & & & & & \\
\hline Two or more times per week & & 8 & $4 \cdot 0$ & - & - & - \\
\hline One time per week & & 5 & 2.5 & - & - & \\
\hline Two to three times per month & & 13 & $6 \cdot 5$ & - & - & \\
\hline Once a month & & 19 & $9 \cdot 6$ & - & - & \\
\hline A few times per year & & 40 & $20 \cdot 1$ & - & - & \\
\hline Never & & 114 & $57 \cdot 3$ & - & - & \\
\hline
\end{tabular}

FV, fruit and vegetable; SSB, sugar-sweetened beverage. 


\section{Farmers' market shopping}

Eighty-five participants (43\%) had been to a farmers' market or produce stand in the past 12 months. The mean farmers' market awareness score was 5.3 out of a possible score of 32. Seventy-one (37\%) participants were aware of the market closest to their residential address. The percentage of participants who were aware of the market closet to their home was statistically significantly greater among those who ever $v$. never visited a farmers' market $(53.8 \% v$. $25.5 \%$, $P<0.001)$. The mean objectively measured distance to the closest farmers' market (from participants' homes) was $4.5 \mathrm{~km}$ ( 2.8 miles), while the mean objectively measured distance to the most frequently visited farmers' market was $15.0 \mathrm{~km}(9.3$ miles) and the mean self-reported distance to the most frequently visited farmers' market was $19.8 \mathrm{~km}$ (12.3 miles). Twenty-three (12\%) participants shopped at the farmers' market closest to their residential address (data not shown). In addition, we found that the market where the most (32\%) participants shopped was 13.95 (SD 8.0) km (8.67 (SD 5.0) miles) from participants' homes.

Table 1 also shows differences between study participants who reported never $v$. ever shopping at farmers' markets. SNAP participants who reported ever shopping at a farmers' market reported consuming 4.7 servings of $\mathrm{FV}$ per day $v .3 .6$ servings for SNAP participants who reported never shopping at farmers' markets. Although not statistically significant, SNAP participants who reported never shopping at farmers' markets consumed more SSB and fast food than those who reported shopping at farmers' markets. Awareness of local farmers' markets was higher among farmers' market shoppers $v$. non-shoppers, whereas farmers' market shoppers lived further from the closest farmers' market than did non-shoppers.

\section{Barriers to and facilitators of farmers' market shopping}

Table 2 shows a wide variety of responses regarding barriers to and facilitators of farmers' market shopping. The top five barriers to shopping at farmers' markets included: does not accept SNAP/electronic benefit transfer (EBT), out of the way, lack of transportation, lack of knowledge of market locations and high prices. The top five facilitators were: fresher produce, better prices, support for local farmers, accepts SNAP/EBT and quality of the products. Hand-written barriers included 'Too far', 'never really thought of it', 'no money', 'food is dirty', 'expensive', 'hours unknown', 'no frozen products', 'convenience', 'mold' and 'transportation.' Hand-written facilitators included 'meat', 'produce curiosity', 'freshness', 'to get kids to eat fruits and veggies', 'WIC coupons', 'salad', 'ease of shopping' and 'might pass by and will stop'.

\section{Associations between farmers' market shopping and awareness, dietary behaviours and BMI}

In multivariable linear regression analyses, farmers' market shopping was associated with awareness of farmers'
Table 2 Barriers to and facilitators of farmers' market shopping among Supplemental Nutrition Program (SNAP) participants in eastern North Carolina, USA, April-July 2013

\begin{tabular}{|c|c|c|}
\hline & Frequency & Percentage \\
\hline \multicolumn{3}{|l|}{ Barriers } \\
\hline $\begin{array}{l}\text { Does not accept SNAP/food stamps/ } \\
\text { EBT }\end{array}$ & 38 & $20 \cdot 9$ \\
\hline Out of the way & 21 & 11.5 \\
\hline I don't have transportation to the market & 20 & 11.0 \\
\hline I don't know where any markets are & 19 & $10 \cdot 4$ \\
\hline Prices are too high & 15 & $8 \cdot 2$ \\
\hline I get what I need from other places & 13 & $7 \cdot 1$ \\
\hline Bad weather & 12 & $6 \cdot 6$ \\
\hline Market day/hours are not convenient & 7 & 3.9 \\
\hline Not enough parking & 2 & $1 \cdot 1$ \\
\hline No credit/debit accepted & 0 & 0.0 \\
\hline \multicolumn{3}{|l|}{ Facilitators } \\
\hline Fresher produce & 93 & $50 \cdot 3$ \\
\hline Better prices & 19 & $10 \cdot 3$ \\
\hline Support local farmers & 15 & $8 \cdot 1$ \\
\hline Accepts SNAP/EBT & 13 & $7 \cdot 0$ \\
\hline Quality of the products & 9 & 4.9 \\
\hline Variety of the products & 6 & 3.2 \\
\hline Produce tastes better & 4 & $2 \cdot 2$ \\
\hline It is close to home & 3 & 1.6 \\
\hline Convenient location & 3 & 1.6 \\
\hline Produce is grown with fewer pesticides & 3 & 1.6 \\
\hline Good service & 1 & 0.5 \\
\hline It is close to work & 1 & 0.5 \\
\hline Friendly atmosphere & 1 & 0.5 \\
\hline Consistency of the products & 0 & 0.0 \\
\hline
\end{tabular}

EBT, electronic benefit transfer.

markets (estimate $=0 \cdot 18$ (se 0.04), $P<0 \cdot 0001)$ but was not significantly associated with age, race, sex, education, distance to farmers' markets or public transportation. When adjusted for age, race, sex, education and public transportation, FV consumption was positively associated with farmers' market shopping (estimate $=1.07$ (sE 0.33), $P=0.0013)$. In multivariate models, neither corrected nor uncorrected BMI was associated with farmers' market shopping. Total energy from SSB consumed and fast-food consumption were not statistically significantly associated with farmers' market shopping.

\section{Discussion}

Among SNAP participants in the present study, the prevalence of farmers' market shopping in the past 12 months was $42.7 \%$. This is similar to other studies which have found that prevalence of farmers' market shopping in this population was $32-40 \%{ }^{(27)}$. Farmers' market shopping was associated with awareness of farmers' market locations. This supports another finding from the present study that a main barrier to farmers' market use is lack of knowledge of farmers' market locations, and is in line with findings that a barrier to farmers' market shopping was lack of knowledge of market locations ${ }^{(26)}$. Alternatively, it could be that those who were more interested in farmers' markets were more likely to take steps to find out the 
market locations. The mean distance to the most frequently visited farmers' market was $\sim 14 \mathrm{~km}$ ( $\sim$ miles) from the individuals' home address, while the perceived distance was greater $(\sim 20 \mathrm{~km}(\sim 12$ miles $))$, indicating that individuals perceive the distance as much greater than it actually is. The market where the most (32\%) participants shopped was the County Farmers' Market, which is very well advertised, has competitive pricing, has many vendors, and accepts WIC Farmers' Market vouchers and Senior Farmers' Market Nutrition Program vouchers (but not SNAP/EBT). Taken together, these results indicate that a main facilitator of farmers' market shopping may not necessarily be making the markets closer to individuals, but making individuals aware of proximal markets and the amenities offered at each.

As found by Grin et $a l^{(35)}$ and Jilcott Pitts et $a l^{(16)}$, shopping at farmers' markets was associated with greater FV consumption. As a dietary pattern characterized by consumption of FV can reduce food-related greenhouse gas emissions $^{(14)}$, it is important for environmental as well as nutritional reasons to determine ways to increase population-level produce consumption. The positive association seen between farmers' market shopping and produce consumption also suggests that efforts to increase farmers' market shopping among low-income consumers could improve diet quality and health. However, these associations may also be a result of a healthier eating identity among those who shop at farmers markets ${ }^{(36)}$ compared with those who do not shop at farmers' markets. Previously mentioned, Young et $a l^{(22)}$ suggest that when incentive programmes are provided at farmers' markets in low-income areas, providing greater financial access to markets, participants report eating more FV than nonparticipants. However, in the current study, neither objectively measured nor perceived access (distance) to farmers' markets was associated with farmers' market use. In fact, those who shopped at farmers' markets lived further from markets than those who did not report shopping at farmers' markets. Increasingly, there are programmatic and policy efforts to increase geographic access to healthy food sources such as farmers' markets. Findings of the current study suggest that it may be at least as important to promote other types of access, such as financial access (through Double Bucks programmes), awareness or social access (including comfort with market culture) ${ }^{(37)}$, to promote farmers' market shopping among low-income consumers. To promote consumption of healthy and sustainable $\mathrm{FV}^{(13)}$, more work is needed to determine how to ameliorate financial, social and geographic access barriers to farmers' market shopping among low-income consumers.

The top barrier to farmers' market shopping among SNAP participants was 'Does not accept SNAP/food stamps/EBT'. One way to improve financial and social access is by expanding SNAP/EBT access and promotion at farmers' markets, which could also create significant gains for small and mid-sized farmers who sell their produce in such direct farm-to-consumer venues. Expanding SNAP/EBT access would encourage sustainability through promoting local and organic FV and improving transparency, as consumers can ask questions directly of farmers. Currently, Pitt County does not have any farmers' markets with SNAP/EBT access, but state-wide efforts are underway to increase access this resource in farmers' markets.

It is important to examine associations between farmers' market use and dietary behaviours other than FV consumption, because increased FV consumption alone will not necessarily have a beneficial impact on obesity among SNAP participants unless such healthy dietary behaviours displace less healthy dietary behaviours (e.g. SSB and fastfood consumption) ${ }^{(31)}$. Thus, we examined associations between farmers' market shopping and SSB and fast-food consumption. However, we did not find statistically significant associations between farmers' market use and other dietary behaviours (SSB and fast-food consumption). This may be because of limited power to detect significant effects due to a small sample size.

Study strengths include the use of valid and reliable measures of FV and SSB consumption in an understudied population. We also used an objective measure of distance to farmers' markets and multiple measures of access to farmers' markets. We examined the association between farmers' market use and less healthy dietary behaviours (SSB and fast-food consumption). Limitations include the use of a small, convenience sample, the potential for diet measurement error, inability to validate SNAP enrolment, and systematic bias in self-reported height and weight to calculate BMI (although we attempted to correct for this). Another limitation includes the dichotomous measure of farmers' market shopping frequency (never $v$. ever buying produce at a farmers' market in the past 12 months). Finally, as this is a cross-sectional analysis, causality cannot be inferred.

Future research should focus on the effects of farmers' market shopping on overall diet quality and on consumption of healthy and sustainable foods. Barriers to shopping at farmers' markets, including markets not accepting SNAP/EBT, market locations being out of the way, lack of transportation, lack of knowledge of market locations and high prices, should be addressed in future interventions to increase SNAP participants' use of farmers' markets. Facilitators such as the ability to procure fresher produce, better prices, support for local farmers, accepting SNAP/EBT and quality of the products should be emphasized in future interventions. Future interventions should also evaluate whether increasing awareness of proximity to farmers' markets translates to increased shopping frequency at farmers' markets.

\section{Acknowledgements}

Acknowledgements: The authors thank Nadya Majette and Matthew McConaughey for help in reviewing the literature. 
Financial support: This work was supported in part by the East Carolina University Department of Public Health and in part by a cooperative agreement with the Centers for Disease Control and Prevention (CDC) (grant number FOA CDC-RFA-DP11-1115PPHF11). Portions of this project's work involve the Communities Transformation Grant initiative supported by CDC funding. However, the findings and conclusions in this paper are those of the authors and do not necessarily represent the official position of the Centers for Disease Control and Prevention. Conflict of interest: None. Authorship: S.B.J.P. formulated the research question, designed the study and drafted the manuscript. Q.W. contributed to study design, analysed the data and helped interpret the data. C.E.D. and C.L.D. collected the data, contributed to study design and data analysis and interpretation. C.J.M.D. contributed to data analysis and interpretation, as well as assisted in the literature review. S.L.B., J.M., R.W. and A.S.A. contributed to study design, interpretation of data analysis and manuscript preparation. All authors reviewed and provided critical intellectual feedback on the manuscript. Ethics of human subject participation: This study was reviewed and approved by the East Carolina University Institutional Review Board.

\section{References}

1. Landers PS (2007) The food stamp program: history, nutrition education, and impact. J Am Diet Assoc 107, 1945-1951

2. Leung CW, Ding EL, Catalano PJ et al. (2012) Dietary intake and dietary quality of low-income adults in the Supplemental Nutrition Assistance Program. Am J Clin Nutr 96 , 977-988.

3. Leung CW, Cluggish S, Villamor E et al. (2014) Few changes in food security and dietary intake from short-term participation in the Supplemental Nutrition Assistance Program among low-income Massachusetts adults. J Nutr Educ Behav 46, 68-74.

4. Leung CW, Blumenthal SJ, Hoffnagle EE et al. (2013) Associations of food stamp participation with dietary quality and obesity in children. Adolesc Med State Art Rev 131, 463-472.

5. Andreyeva T, Luedicke J, Henderson KE et al. (2012) Grocery store beverage choices by participants in federal food assistance and nutrition programs. Am J Prev Med 43, 411-418.

6. Leung CW, Willett WC \& Ding EL (2012) Low-income Supplemental Nutrition Assistance Program participation is related to adiposity and metabolic risk factors. Am J Clin Nutr 95, 17-24.

7. Jilcott SB, Liu H, Dubose KD et al. (2011) Food stamp participation is associated with fewer meals away from home, yet higher body mass index and waist circumference in a nationally representative sample. J Nutr Educ Behav $\mathbf{4 3}$ $110-115$.

8. Watt TT, Appel L, Roberts K et al. (2013) Sugar, stress, and the Supplemental Nutrition Assistance Program: early childhood obesity risks among a clinic-based sample of low-income Hispanics. J Community Health $\mathbf{3 8}$, 513-520.

9. Hartley L, Igbinedion E, Holmes J et al. (2013) Increased consumption of fruit and vegetables for the primary prevention of cardiovascular diseases. Cochrane Database Syst Rev 6, CD009874.

10. Boeing H, Bechthold A, Bub A et al. (2012) Critical review: vegetables and fruit in the prevention of chronic diseases. Eur J Nutr 51, 637-663.

11. Swinburn BA, Caterson I, Seidell JC et al. (2004) Diet, nutrition and the prevention of excess weight gain and obesity. Public Health Nutr 7, 123-146.

12. Hu FB (2013) Resolved: there is sufficient scientific evidence that decreasing sugar-sweetened beverage consumption will reduce the prevalence of obesity and obesity-related diseases. Obes Rev 14, 606-619.

13. Friel S, Barosh LJ \& Lawrence M (2014) Towards healthy and sustainable food consumption: an Australian case study. Public Health Nutr 17, 1156-1166.

14. Weber CL \& Matthews HS (2008) Food-miles and the relative climate impacts of food choices in the United States. Environ Sci Technol 42, 3508-3513.

15. Sharkey JR, Johnson CM \& Dean WR (2010) Food access and perceptions of the community and household food environment as correlates of fruit and vegetable intake among rural seniors. BMC Geriatr 2, 32.

16. Jilcott Pitts SB, Wu Q, McGuirt JT et al. (2013) Associations between access to farmers' markets and supermarkets, shopping patterns, fruit and vegetable consumption and health indicators among women of reproductive age in eastern North Carolina, USA. Public Health Nutr 16, 1944-1952.

17. Caspi CE, Kawachi I, Subramanian SV et al. (2012) The relationship between diet and perceived and objective access to supermarkets among low-income housing residents. Soc Sci Med 75, 1254-1262.

18. Academy of Nutrition and Dietetics (formerly American Dietetics Association), American Nurses Association, American Planning Association et al. (2010) Principles of a healthy, sustainable food system. https://www.planning.org/ nationalcenters/health/pdf/HealthySustainableFoodSystems Principles_2012May.pdf (accessed September 2014).

19. Stagl S (2002) Local organic food markets: potentials and limitations for contributing to sustainable development. Empirica 29, 145-162.

20. McCormack LA, Laska MN, Larson NI et al. (2010) Review of the nutritional implications of farmers' markets and community gardens: a call for evaluation and research efforts. J Am Diet Assoc 110, 399-408.

21. Millichamp A \& Gallegos D (2013) Comparing the availability, price, variety and quality of fruits and vegetables across retail outlets and by area-level socio-economic position. Public Health Nutr 16, 171-178.

22. Young CR, Aquilante JL, Solomon S et al. (2013) Improving fruit and vegetable consumption among low-income customers at farmers markets: Philly Food Bucks, Philadelphia, Pennsylvania, 2011. Prev Chronic Dis 3, E166.

23. Baronberg S, Dunn L, Nonas C et al. (2013) The impact of New York City's Health Bucks Program on electronic benefit transfer spending at farmers markets, 2006-2009. Prev Chronic Dis 26, E163.

24. NC Department of Health and Human Services (2011) North Carolina Awarded \$7.4 Million to Help Create Healthier Communities. Press release, 27 September. http://www.ncdhhs.gov/pressrel/2011/2011-09-27_NC_ awarded.htm (accessed September 2011).

25. McGuirt JT, Jilcott SB, Liu H et al. (2011) Produce price savings for consumers at farmers' markets compared to supermarkets in North Carolina. J Hunger Environ Nutr 6, 86-98.

26. Leone LA, Beth D, Ickes SB et al. (2012) Attitudes toward fruit and vegetable consumption and farmers' market usage among low-income North Carolinians. J Hunger Environ Nutr 7, 64-76. 
27. Racine EF, Smith VA \& Laditka SB (2010) Farmers' market use among African-American women participating in the Special Supplemental Nutrition Program for Women, Infants, and Children. J Am Diet Assoc 110, 441-446.

28. Carman T (2014) Farm bill contains farmers' market program that food advocates for poor see as hopeful. The Washington Post, 30 January. http://www.washingtonpost.com/lifestyle/ food/farm-bill-contains-farmers-market-program-that-foodadvocates-for-poor-see-as-hopeful/2014/01/30/b86c9b74-89e311e3-833c-33098f9e5267_story.html (accessed January 2014).

29. Ritenbaugh P, Ritenbaugh C, Treiber F et al. (1993) Evaluation of a brief telephone questionnaire to estimate fruit and vegetable consumption in diverse study populations. Epidemiology 4, 455-463.

30. Block G, Gillespie C, Rosenbaum EH et al. (2000) A rapid food screener to assess fat and fruit and vegetable intake. Am J Prev Med 8, 284-288.

31. Bontrager Yoder $\mathrm{AB} \&$ S Schoeller DA (2014) Fruits and vegetables displace, but do not decrease, total energy in school lunches. Child Obes 10, 357-364.
32. Hendrick VE, Comber DL, Estabrooks PA et al. (2010) The beverage intake questionnaire: initial validity and reliability. J Am Diet Assoc 110, 1227-1232.

33. Anderson B, Rafferty AP, Lyon-Callo S et al. (2011) Fast-food consumption and obesity among Michigan adults. Prev Chronic Dis 8, A71.

34. Jain RB (2010) Regression models to predict corrected weight, height and obesity prevalence from self-reported data: sata from BRFSS 1999-2007. Int J Obes (Lond) 34, 1655-1664.

35. Grin BM, Gayle TL, Saravia DC et al. (2013) Use of farmers' markets by mothers of WIC recipients, Miami-Dade County, Florida. 2011. Prev Chronic Dis 10, 120178.

36. Blake CE, Freedman DA, Bell BA et al. (2013) The Eating Identity Inventory (EITI). Development and associations with diet. Appetite 69, 15-22.

37. McGuirt JT, Ward R, Elliot NM et al. (2014) Factors influencing local food procurement among women of reproductive age in rural eastern and western North Carolina, USA. J Agric Food Syst Community Dev 4, 143-154. 